\title{
O CORPO NA PSICANÁLISE CONTEMPORÂNEA: SOBRE AS CONCEPÇÕES PSICOSSOMÁTICAS DE Pierre MarTy E Joyce McDougall
}

Rodrigo Sanches Peres*

\section{Resumo}

Este estudo tem como objetivo apresentar algumas considerações a respeito das concepções teóricas de Pierre Marty e Joyce McDougall. Tal propósito justifica-se tendo em vista que os referidos autores se afiguram como dois dos mais importantes expoentes da psicossomática psicanalítica e, assim, oferecem contribuições de grande valor para a compreensão dos determinantes psicológicos das enfermidades orgânicas. Além disso, vale destacar que Marty e McDougall acrescentam à psicanálise conceitos que ainda não foram devidamente incorporados à literatura científica especializada. Conseqüentemente, considerou-se relevante focalizar no presente estudo a discussão de dois desses conceitos, a saber: pensamento operatório e desafetação.

Palavras-chave: psicossomática, psicanálise, pensamento operatório, desafetação, somatização

\section{Abstract}

The body on COntemporary psychoanalysis: about Pierre Marty's and Joyce MCDOUGALL'S PSYCHOSOMATIC CONCEPTIONS

This paper has as purpose present some considerations on Pierre Marty's and Joyce McDougall's theoretical conceptions. Such purpose is justified because the referred authors are two of the most important exponents of psychoanalytical psychosomatic and, thus, offer great relevance contributions for understanding of organic illnesses' psychological determinant. Besides, Marty and McDougall introduce concepts on psychoanalysis those are not still properly incorporate

* Psicólogo pela Universidade Estadual Paulista (UNESP), Mestre e Doutorando em Psicologia pela Universidade de São Paulo (USP), Docente da Universidade Federal de São Carlos (UFSCar). 
to the specialized scientific literature. Consequently, was considered relevant to focus in this paper the discussion of two of those concepts: operational thinking and disaffection.

Keywords: psychosomatic, psychoanalysis, operational thinking, disaffection, somatization

\section{PSICANÁliSE E PSICOSSOMÁTICA: APROXIMAÇÕES INICIAIS}

No final do século XIX, o médico austríaco Sigmund Freud (1856-1939) provoca uma mudança de paradigma com a descoberta do inconsciente e a fundação de uma nova teoria sobre os processos psíquicos. A partir dos revolucionários estudos sobre a histeria executados com a colaboração do psiquiatra francês Jean Martin Charcot (1825-1893), o até então eminente neurologista propõe que as doenças orgânicas não são decorrentes apenas de agentes biológicos e que o corpo é susceptível também às vicissitudes da mente. Nesse sentido, rompe com o modelo cartesiano vigente até então, pois aponta, conforme Aisenstein (1994) e Volich (2000), que a saúde de um indivíduo se encontra intimamente relacionada à sua própria história.

A preocupação com a questão do corpo foi, portanto, fundamental para o surgimento da psicanálise (Cukiert \& Priszkulnik, 2000). No desenvolvimento de sua teoria, contudo, Freud optou - devido a motivos meramente didáticos, segundo Haynal e Pasini (1983) - por dedicar maior atenção à pesquisa das afecções mentais e, conseqüentemente, colocou em segundo plano a investigação dos fatores psíquicos associados à eclosão de doenças orgânicas. Todavia, foi responsável, como destacam Rodrigues e Rodrigues (1991), pela instituição dos pressupostos que serviram de base para que outros autores pudessem, em um segundo momento, retomar a tese hipocrática da unidade funcional entre o biológico e o psicológico.

Os pioneiros na utilização dos postulados metapsicológicos na tentativa de identificação dos determinantes emocionais das doenças orgânicas foram o psicanalista húngaro Sándor Ferenczi (1873-1933) e o médico alemão Georg Groddeck (1866-1934). No entanto, ambos se apropriaram indevidamente das premissas psicanalíticas acerca da etiologia da histeria, posto que, como salienta Del Vogo (1998), procuravam, cada um a seu modo, analisar as doenças orgânicas como o produto simbólico da ação de um mecanismo puramente mental: a conversão. Dessa maneira, forjaram hipóteses extremistas que conduziram a um reducionismo do complexo "salto do psíquico para o somático".

Um novo movimento psicossomático inspirado no pensamento freudiano começou a surgir a partir de 1930 com Franz Alexander (1891-1964). Psicanalis- 
ta húngaro radicado nos Estados Unidos da América, o mesmo afirmava que certos conflitos psíquicos provocam disfunções do sistema nervoso autônomo, desencadeando alterações nos músculos lisos e produzindo secreções glandulares desordenadas (Santos Filho, 1993). Assim sendo, defendia, conforme Haynal e Pasini (1983), que as doenças orgânicas poderiam ser entendidas basicamente como respostas fisiológicas exacerbadas decorrentes de estados de tensão emocional crônica motivados por processos mentais inconscientes desprovidos de significado simbólico.

Porém tais proposições foram questionadas nas décadas seguintes por autores que acreditavam que o modelo psicossomático de base psicofisiológica de Alexander se apoiava em uma visão dualista do homem. Endossando esses questionamentos, diversos psicanalistas franceses se organizaram com o intuito de delinear uma nova via de formação das manifestações corporais do sofrimento emocional. Liderados por Pierre Marty (1918-1993), entendiam que pacientes somáticos ${ }^{1}$ se caracterizam por um modo de funcionamento psíquico distinto daquele apresentado por neuróticos e psicóticos (Volich, 2000). Ademais, postulavam que as doenças orgânicas devem ser analisadas a partir de uma perspectiva de continuidade evolutiva e funcional entre o corpo anatômico e o corpo erógeno, como destaca Vieira (1997).

O modelo formulado por Marty e seus colaboradores é apontado pela literatura científica especializada como uma das vertentes psicossomáticas mais consistentes, pois possibilita o esclarecimento de alguns dos complexos processos subjacentes à interação mente-corpo (Ferraz 1997; Horn \& Almeida, 2003; Santos Filho, 1994; Silva \& Caldeira, 1993; Smadja, 1995). Faz-se necessário salientar, contudo, que a psicossomática psicanalítica não se reduz a esse modelo. Nas décadas de 70, 80 e 90, uma série de autores se empenhou em repensar o papel do psíquico como dimensão constitutiva do processo saúde-doença. A maioria deles, não obstante, enveredou por percursos teóricos distintos, em maior ou menor grau, daqueles preconizados por Marty.

Joyce McDougall, neozelandesa radicada na França, indubitavelmente pode ser considerada um dos principais nomes da psicossomática psicanalítica nos dias de hoje (Peres, no prelo). Capaz de se manter alheia a sectarismos e transitar por diversas escolas teóricas, não hesita, como aponta Menahem (2001), em buscar respostas para seus questionamentos junto a autores que adotam teses paradoxais. Além disso, se preocupa em problematizar suas próprias idéias quando se depara com os impasses inerentes à prática clínica, permitindo-se trazer à luz novas hipóteses sobre as facetas psíquicas das doenças orgânicas (Ceccarelli, 1997; Montagna, 1988). 
O presente estudo tem como objetivo alinhavar algumas considerações a respeito das concepçōes teóricas de Marty e McDougall, valendo-se, para tanto, de textos dos referidos autores e de seus mais expressivos comentadores. Tal propósito justifica-se tendo em vista que ambos se destacam como dois dos mais relevantes expoentes da psicossomática psicanalítica e, assim, oferecem contribuições de grande valor para a compreensão do instigante objeto ao qual se dedicam. Ressalte-se também que acrescentam conceitos que ainda não foram devidamente incorporados à psicanálise. Por essa razão, considerou-se pertinente focalizar a discussão de dois deles, a saber: pensamento operatório e desafetação.

\section{PENSAMENTO OPERATÓRIO: CARÊNCIA FANTASMÁTICA E REATIVIDADE ORGÂNICA}

Em função dos achados oriundos de seus trabalhos clínicos, Marty e M’Uzan (1962/1994) apontaram que usualmente pacientes somáticos apresentam pensamentos superficiais, desprovidos de valor libidinal, excessivamente orientados para a realidade externa e estreitamente vinculados à materialidade dos fatos. Desse modo, sugeriram que os sujeitos em questão se caracterizam por um comprometimento da capacidade de simbolização. Ademais, propuseram que esse comprometimento tende a se desdobrar em uma considerável restrição da atividade fantasmática e em um marcante apagamento de toda expressividade de ordem mental, o que denota a existência de uma carência funcional do psiquismo (Horn \& Almeida, 2003; Silva \& Caldeira, 1993).

Marty (1993) aponta que, levando-se em consideração tais especificidades, poder-se-ia imaginar que a dinâmica afetiva dos pacientes somáticos é regida exclusivamente pelo processo secundário. Os indivíduos em pauta, porém, não estabelecem conexōes com conteúdos simbólicos, evidenciando a ocorrência de investimentos libidinais arcaicos, semelhantes àqueles executados quando o aparelho mental opera sob a égide do processo primário. Conseqüentemente, a energia psíquica - o substrato quantitativo da simbolização - se encontra livre e fomenta a utilização compulsiva dos caminhos mais rápidos e diretos de escoamento das tensões.

Possivelmente por esse motivo, uma veemente propensão à ação em detrimento da simbolização se destaca, de acordo com Marty e M'Uzan (1962/1994), como outra característica dos pacientes somáticos. Condutas pouco elaboradas do ponto de vista psíquico são então adotadas para minimizar o impacto causado pelas excitaçôes. Isso sugere que o inconsciente não consegue se comunicar mediante o emprego de representaçóes e tende a encontrar no comportamento sua 
única possibilidade de expressão. Pode-se supor, diante do exposto, que a restrição fantasmática que os caracteriza faz do aparelho sensório-motor uma via privilegiada de exteriorização das demandas pulsionais (Marty, 1993).

Tal hipótese adquire ainda mais consistência partindo-se do princípio de que, conforme Marty, M'Uzan e David (1967), é possível notar no discurso dos sujeitos em questão que suas palavras freqüentemente se encontram desvinculadas de elementos simbólicos e são empregadas como um mero instrumento de descarga das tensões. Ou seja: suas verbalizações não são sobreinvestidas e tampouco sobredeterminadas. Vale salientar, entretanto, que o psiquismo de pacientes somáticos não se encontra plenamente desligado do inconsciente. Na realidade, contatos arcaicos são mantidos com os conteúdos situados para além da consciência, mas isso não subsidia o desenvolvimento de elaborações integradoras da vida pulsional (Silva \& Caldeira, 1993).

Marty (1998) salienta também que pacientes somáticos geralmente estabelecem vínculos afetivos pouco significativos e sustentam relacionamentos superficiais. Não obstante, em contraste com o que se observa nos casos de neurose obsessiva, essa tendência não se deve à manipulação do material psíquico, já que, como apontado anteriormente, uma importante restrição da capacidade de simbolização os acomete. A propensão ao distanciamento e à manutenção de "relações brancas", portanto, se encontra associada às identificações esquemáticas que amiúde são estabelecidas pelos indivíduos em pauta devido à escassez de seus investimentos libidinais.

Tendo em vista o que precede, Marty e M'Uzan (1962/1994) propuseram que pacientes somáticos comumente apresentam um funcionamento psíquico que se situa entre as neuroses e as psicoses. No início da década de 60, os autores em questão cunharam o termo "pensamento operatório" para lhe fazer referência. Todavia, ao contrário do que seria possível pensar a princípio, esse termo não remete apenas a uma modalidade de pensamento, mas, sim, a um tipo de organização psíquica. As expressões "funcionamento operatório" e "vida operatória", assim, usualmente são empregadas na literatura científica especializada como substitutos do conceito original.

Marty (1993) destaca que o desenvolvimento de suas idéias parte do princípio de que a atividade fantasmática viabiliza o escoamento das excitações, integra as demandas pulsionais e subsidia a formação de sintomas - geralmente mentais, mas ocasionalmente físicos - reversíveis. Nesse sentido, tem como base os pressupostos metapsicológicos clássicos. Ressalte-se, entretanto, que a descrição do pensamento operatório coloca em xeque a suposta capacidade ilimitada de elaboração psíquica da qual, segundo Freud (1914/1996), o homem pode se beneficiar às 
custas do processo de reprodução inconsciente de experiências penosas desencadeado pela compulsão à repetição.

O rearranjo dos elementos funcionais existentes no pré-consciente se torna, segundo Marty e Loriod (1985/2001), particularmente custoso na vida operatória. Em função de esse rearranjo ser uma condição indispensável para a execução dos movimentos psíquicos de organização evolutiva que se fazem necessários ao longo da vida, a substituição da simbolização pela reação biológica deixa de ser principalmente em circunstâncias estressoras - uma prática esporádica e reestruturante, transformando-se em uma ação usual e destrutiva. Seguindo esse raciocínio, o pensamento operatório não deve ser entendido como um mero desdobramento do impacto causado pela ocorrência de uma somatização, mas, sim, como um fator associado ao adoecimento (Vieira, 1997; Ferraz, 1997).

Entretanto, os comportamentos podem, como propôs Freud (1913/1996), substituir a linguagem e o pensamento e promover de forma relativamente satisfatória a descarga das tensōes. Por essa razão, não raro os indivíduos operatórios conseguem, graças à orientação para a ação que apresentam, se proteger da eclosão de afecções orgânicas. Ademais, muitos pacientes somáticos não demonstram qualquer indício de funcionamento operatório. Isso acontece porque o adoecimento, como não se pode perder de vista, é um processo complexo, cujo curso, determinado pela interação de diversos fatores, é irredutível a um único padrão.

É preciso reconhecer, por fim, que Marty e seus colaboradores não elaboraram hipóteses suficientemente esclarecedoras acerca da etiologia do pensamento operatório. O que se postula é que esse modo de funcionamento psíquico se encontra intimamente relacionado a desarmonias afetivas ocorridas na primeira infância em virtude do desempenho inapropriado - excessivo ou insuficiente - da função materna (Marty, 1998). Nesse sentido, pode-se propor que, na maior parte dos casos, indivíduos operatórios foram educados por mães autoritárias, deprimidas, negligentes, superprotetoras ou que, devido a qualquer outro motivo, não se mostraram capazes de proteger seus filhos das tensões que os acometeram no início da vida.

\section{DESAFETAÇÃO: ALIENAÇÃO CORPORAL E RESSOMATIZAÇÃO AFETIVA}

Segundo McDougall (1991), pacientes somáticos geralmente são pouco capazes de elaborar psiquicamente afetos potencialmente desestruturantes. Em função disso, não raro lançam mão de estratégias defensivas arcaicas para evitar a eclosão de mobilizações emocionais que podem fugir a seu controle. Tais opera- 
ções, amiúde, são adotadas de forma inconsciente e envolvem a exclusão sumária de representações carregadas de sentimentos intoleráveis. Depreende-se, portanto, que, como destacam Montagna (1988) e Rocha (1988), os indivíduos em questão simplesmente "ejetam" os afetos do próprio aparelho mental.

Considerando as particularidades desses processos protetores, McDougall (1983) propõe que os mesmos não devem ser comparados à repressão - uma vez que não são executados conscientemente - e tampouco ao recalque - pois não transformam emoções em material inconsciente. Seguindo esse raciocínio, a tendência a "ejetar" do próprio psiquismo percepções, fantasias e pensamentos associados a afetos se assemelha, em seus aspectos principais, a um mecanismo de defesa que, de acordo com Freud (1894a/1996), pode ser considerado dos mais radicais: o repúdio para fora do ego (Verwerfung). Tal recurso não somente promove a exclusão de sentimentos do plano da consciência, mas também leva o indivíduo a agir como se nunca tivesse tido acesso aos conteúdos repudiados.

Não obstante, faz-se necessário destacar que, na concepção freudiana, o repúdio para fora do ego se desdobra no surgimento de fenômenos alucinatórios e delirantes, de maneira que pode ser entendido como uma defesa específica das psicoses. McDougall (1989), por seu turno, propõe que os afetos "ejetados" do aparelho mental de pacientes somáticos não geram como subproduto alucinações ou delírios, mas, sim, se perdem sem qualquer espécie de compensação psíquica. Como conseqüência, tendem, em contraste com o que ocorre com os psicóticos, a ser reduzidos à sua pura expressão somática. Ou seja: a utilização desse expediente pode promover uma cisão entre o corpo anatômico e o corpo erógeno, culminando na ressomatização do afeto (Montagna, 1988).

Tomando como base a hipótese precedente, deduz-se que os afetos de pacientes somáticos usualmente não encontram nenhum dos três destinos descritos por Freud (1894b/1996), posto que, quando excluídos, não são convertidos, deslocados ou transformados, como ocorre, respectivamente, na histeria, na neurose obsessiva e na neurose de angústia ou na melancolia. Desse modo, McDougall (1989) defende que as emoçôes podem - ao contrário do que sugerem os pressupostos metapsicológicos clássicos - efetivamente desaparecer do aparelho psíquico mediante a expulsão do plano consciente de pensamentos, fantasias e representaçōes associadas a afetos capazes de provocar sofrimento.

O emprego de tal estratégia defensiva, porém, tende a produzir um distúrbio da economia afetiva. O neologismo "desafetação" foi criado por McDougall (1984) especialmente para fazer referência a esse distúrbio. Como se sabe, o prefixo latino des sugere separação, perda ou desligamento. Torna-se patente, assim, que a composição do termo indica, por si só, que a patologia em questão 
envolve o rompimento do indivíduo com seus próprios sentimentos. A desafetação, com efeito, leva o sujeito a encontrar dificuldades para apreender contrastes emocionais e discriminar tanto seus afetos quanto os das demais pessoas com as quais convive, conduzindo ao estabelecimento de vínculos pouco consistentes (Bunemer, 1995).

Todavia, o indivíduo desafetado pode - sobretudo em situações de sofrimento psíquico - manter relaçôes fusionais com o intuito de recriar a ilusão primitiva de unidade corporal e mental com a figura materna (McDougall, 1991). Essa ilusão, a propósito, possibilita ao bebê sobreviver às tensões que o acometem, já que fomenta a crença da existência de apenas um corpo para dois seres vivos. $\mathrm{O}$ uso desse expediente, entretanto, tende a tornar o indivíduo gradativamente incapaz de distinguir a si mesmo do outro. Por essa razão, engendra a eclosão de angústias psicóticas que podem ser decodificadas como ameaças biológicas e criar condições favoráveis para o surgimento de somatizações, visto que estimulam o corpo a se pronunciar mediante a utilização dos parcos recursos defensivos dos quais dispõe (Ferraz, 1997).

Ressalte-se também que a desafetação leva o indivíduo a encontrar nos atos - e não no trabalho mental, como fazem os neuróticos - a única possibilidade de escoamento das tensões (Caïn, 1985/2001). Tais atos se afiguram essencialmente como movimentos de exteriorização desprovidos de valor simbólico. Seguindo esse raciocínio, McDougall (1989) propõe que os desafetados procuram compensar com um "agir compulsivo" a restrição da capacidade de simbolização que os caracteriza. Essa compensação, contudo, pode se tornar um "ato-sintoma” e incidir sobre o corpo, pois o mesmo é percebido como um objeto alheio ao psiquismo pelos sujeitos em questão (Rocha, 1988).

Conforme McDougall (1989), perturbações relacionais da díade mãe-bebê se destacam como o fator etiológico central da desafetação. Essa hipótese parte do princípio de que a figura materna tem como principal tarefa exercer a função de pára-excitação, ou seja, proteger seu filho das tensões provenientes do mundo exterior. Para tanto, deve interpretar a comunicação primitiva e nomear os estados afetivos de seu bebê, promovendo a progressiva dessomatização do aparelho mental. $\mathrm{O}$ adequado desempenho dessa tarefa subsidia o acesso da criança à palavra e favorece o desenvolvimento da capacidade de simbolização.

Faz-se necessário salientar ainda que, para McDougall (1989), não se deve associar indiscriminadamente a desafetação à somatização, uma vez que qualquer indivíduo pode apresentar sintomas corporais quando as excitaçōes às quais é submetido fogem a seu controle. Porém usualmente o sujeito que não é portador desse distúrbio da economia afetiva somatiza somente em situações extremas, que 
tornam inoperante o emprego de mecanismos de defesa menos radicais do que o repúdio para fora do ego. Os desafetados, em contrapartida, tendem a ejetar da consciência qualquer sentimento potencialmente desestruturante e, como conseqüência, são impelidos a apresentar reações orgânicas perante o sofrimento mental com maior freqüência e intensidade.

\section{SOFRIMENTO CORPORAL E (A AUSÊNCIA DE) SIGNIFICADO SIMBÓLICO}

Diante do exposto, é possível concluir que o acionamento dos mecanismos de produção dos sintomas corporais apresentados por pacientes somáticos pode ser facilitado, segundo Marty (1993), pela execução de investimentos libidinais arcaicos, ou, conforme McDougall (1991), pela utilização de recursos defensivos primitivos. Evidencia-se, assim, que há uma divergência importante entre as propostas teóricas dos referidos autores. Todavia, ambos postulam que esses sujeitos se caracterizam por uma marcante restrição da capacidade de elaboração psíquica. Em função disso, tanto Marty quanto McDougall entendem as afecçôes orgânicas potencializadas pelo pensamento operatório ou pela desafetação como manifestaçôes desprovidas de valor simbólico.

Como se sabe desde o advento do inconsciente, a histeria possui um significado metafórico, posto que a repressão - mecanismo de formação de sintomas do qual decorre - tem uma natureza exclusivamente psíquica. Por essa razão, o modelo etiológico de tal psicopatologia não é empregado por Marty e tampouco por McDougall na tentativa de compreensão dos fatores emocionais associados ao adoecimento de pacientes somáticos. Em última análise, ambos defendem que os sujeitos em questão são vítimas de um fenômeno análogo àquele que, segundo Freud (1926/1996), engendra o desenvolvimento das neuroses atuais, a saber: a transformação direta da excitação em angústias automáticas.

A literatura psicanalítica clássica preconiza que os sintomas físicos da neurose de angústia, da neurastenia e da hipocondria, isto é, dos quadros clínicos que compõem a referida classe nosográfica, têm como fator desencadeante a ação de processos totalmente somáticos, de modo que não podem ser considerados uma expressão simbólica. Tendo em vista que esses processos são causados por lacunas no aparelho mental que favorecem a tradução corporal de uma história sem palavras, Marty e McDougall propuseram que, em termos etiológicos, a somatização está muito mais próxima da neurose atual do que da histeria. Com essa tese, a propósito, revolucionaram a psicossomática e ampliaram os limites da metapsicologia. 
Os referidos autores também assumem posiçōes teóricas semelhantes ao afirmar que a expressão corporal de conflitos emocionais se afigura, nas neuroses, como uma medida eventual, funcional e dotada de pouco poder destrutivo. $\mathrm{O}$ funcionamento operatório e a desafetação, em contraste, implicam, cada qual a seu modo, a utilização recorrente do artifício em questão, o que favorece o surgimento de enfermidades mais severas. Dessa maneira, ambos defendem que indivíduos que possuem essas características são portadores de uma vulnerabilidade psicossomática acentuada e não devem ser comparados com aqueles que apresentam sintomas orgânicos ocasionais (Peres \& Santos, no prelo).

Ressalte-se ainda que, para Marty (1993), a utilização do termo "psicossomático" como adjetivo remete ao antigo dualismo cartesiano. Seguindo esse raciocínio, afirmar que uma dada doença é psicossomática encerra uma marcante falácia. McDougall (1991) compartilha dessa opinião, o que torna patente que ambos concordam que a unicidade mente-corpo faz do homem um ser psicossomático por definição. Não obstante, os referidos autores reconhecem a multicausalidade do adoecimento e não atribuem exclusivamente a determinantes psíquicos a eclosão de enfermidades somáticas. Em virtude da complexidade de tal processo, contudo, inegavelmente privilegiam a análise dos fatores emocionais associados a esse processo.

Essa opção metodológica, cumpre assinalar, não se apresenta como um reducionismo psicológico semelhante àquele forjado nos primórdios da psicossomática psicanalítica, mas, sim, como um recorte necessário diante das múltiplas facetas do fenômeno que se propõem analisar. Ou seja: é perfeitamente compatível com o modelo biopsicossocial de compreensão do processo saúde-doença vigente nos dias de hoje. Ademais, as proposiçôes de Marty e McDougall não excluem outras tentativas de explicação da gênese de enfermidades orgânicas - sejam elas médicas, culturais, sociais ou de outro caráter - apoiadas em elementos conceituais de raciocínio distintos (Peres, 2004).

Por fim, vale destacar que Marty e McDougall estão de acordo que, nos casos em que a figura materna não cumpre de forma apropriada a função de páraexcitação, os sinais pré-verbais que o bebê emite não são inseridos em um código lingüístico. As experiências que a criança vive não serão, portanto, devidamente simbolizadas e seu corpo se apresentará como a via privilegiada de exteriorização de seus conflitos, engendrando o desenvolvimento de somatizações. Em suma: para ambos, o corpo anatômico se torna erógeno como resultado de um processo gradativo e complexo que tem início nos primeiros meses de vida.

O presente estudo aponta que a articulação entre as contribuições teóricas de Marty e McDougall é um recurso pertinente para a elucidação do papel dos 
fatores emocionais tanto no surgimento quanto no curso das doenças orgânicas. Obviamente, porém, essa aproximação não deve ser executada de forma ingênua, já que existem importantes incongruências entre o pensamento dos referidos autores. É preciso reconhecer também que nenhum deles tem a pretensão de esgotar o assunto. Todavia, suas proposições são dotadas de um valor inquestionável, pois, no atual estágio do conhecimento, as relaçōes entre o biológico e o psicológico podem ser consideradas tão fascinantes quanto misteriosas.

\section{REFERÊNCIAS BIBLIOGRÁFICAS}

Aisenstein, M. (1994). Da medicina à psicanálise e à psicossomática (J. M. Canelas Neto, Trad.). Revista Brasileira de Psicanálise, 28 (1), 99-110.

Bunemer, E. (1995). Desafetação: a dificuldade de investir no objeto. IDE, 26, 28-42.

Caïn, J. (2001). Contratransferência e psicossomática. (L. Y. Massuh, Trad.). Em McDougall, J., Gachelin, G., Aulagnier, P., Marty, P., Loriod, J. \& Caïn, J. (Orgs.). Corpo e história (pp. 213-266). São Paulo: Casa do Psicólogo, 1985.

Ceccarelli, P. R. (1997). Joyce McDougall: uma apresentação. Percurso, 18, 104-106.

Cukiert, M. \& Priszkulnik, L. (2000). O corpo em psicanálise: algumas considerações. Psychê, 5, 53-63.

Del Vogo, M. J. (1998). O instante de dizer: o mito individual do doente sobre a medicina moderna (M. Gambini, Trad.). São Paulo: Escuta.

Ferraz, F. C. (1997). Das neuroses atuais à psicossomática. Em Ferraz, F. C. \& Volich, R. M. (Orgs.). Psicossoma: psicossomática psicanalítica (pp. 23-38). São Paulo: Casa do Psicólogo.

Freud, S. (1894a). As neuropsicoses de defesa (M. Salomão, Trad.). Em Salomão, J. (Org.). Edição standard brasileira das obras psicológicas completas de Sigmund Freud, vol. III (pp. 53-66). Rio de Janeiro: Imago, 1996.

. (1894b). Carta 18 (J. L. Meuer, Trad.). Em Salomão, J. (Org.). Edição standard brasileira das obras psicológicas completas de Sigmund Freud, vol. I (pp. 233-234). Rio de Janeiro: Imago, 1996.

. (1913). O retorno do totemismo na infância (O. C. Muniz, Trad.). Em Salomão, J. (Org.). Edição standard brasileira das obras psicológicas completas de Sigmund Freud, vol. XIII (pp. 109-162). Rio de Janeiro: Imago, 1996.

. (1914). Recordar, repetir e elaborar (J. O. A. Abreu, Trad.). Em Salomão, J. (Org.). Edição standard brasileira das obras psicológicas completas de Sigmund Freud, vol. XII (pp. 163-171). Rio de Janeiro: Imago, 1996. 
. (1926). Inibições, sintomas e angústia (C. M. Oiticica, Trad.). Em Salomão, J. (Org.). Edição standard brasileira das obras psicológicas completas de Sigmund Freud, vol. XX (pp. 91-152). Rio de Janeiro: Imago, 1996.

Haynal, A. \& Pasini, W. (1983). Manual de medicina psicossomática (M. C. R. Barbosa, R. L. Lana \& R. R. Josef, Trads.). São Paulo: Masson.

Horn, A. \& Almeida, M. C. P. (2003). Sobre as bases freudianas da psicossomática psicanalítica: um estudo sobre as neuroses atuais. Revista Brasileira de Psicanálise, 37 (1), 6984.

Marty, P. (1993). A psicossomática do adulto (P. C. Ramos, Trad.). Porto Alegre: Artes Médicas.

Marty, P. (1998). Mentalização e psicossomática (A. E. V. A. Güntert, Trad.). São Paulo: Casa do Psicólogo.

Marty, P. \& Loriod, J. (1985). Funcionamento mental e funcionamento somático (L. Y. Massuh, Trad.). Em McDougall, J., Gachelin, G., Aulagnier, P., Marty, P., Loriod, J. \& Caïn, J. (Orgs.). Corpo e história (pp. 151-211). São Paulo: Casa do Psicólogo, 2001.

Marty, P. \& M’Uzan, M. (1962). O pensamento operatório (V. A. C. Beusson, Trad.). Revista Brasileira de Psicanálise, 28 (1), 1994, 165-174.

Marty, P., M’Uzan, M. \& David, C. (1967). Investigation psychosomatique. Paris: Presses Universitaires de France.

McDougall, J. (1983). Em defesa de uma certa anormalidade (C. E. Reis, Trad.). Porto Alegre: Artes Médicas.

. (1984). The "dis-affected" patient: reflections on affect pathology. Psychoanalytic Quarterly, 53, 386-409.

- (1989). Teatros do eu (O. Coddá, Trad.). Rio de Janeiro: Francisco Alves. . (1991). Teatros do corpo (P. H. B. Rondon, Trad.). São Paulo: Martins Fontes.

Menahem, R. (2001). Joyce McDougall (M. Seincman, Trad.). São Paulo: Via Lettera.

Montagna, P. (1988). A respeito de Joyce McDougall. IDE, 16, 39-41.

Peres, R. S. (2004). A exclusão do afeto e a alienação do corpo: contribuições da psicossomática psicanalítica para a compreensão da personalidade de pacientes com indicação para o transplante de medula óssea. Dissertação de Mestrado. Programa de Pós-Graduação em Psicologia, Universidade de São Paulo, Ribeirão Preto, SP.

(no prelo). A psicanálise no divã. Paidéia.

Peres, R.S. \& Santos, M. A. (no prelo). Pensamento operatório, desorganização progressiva e somatização: consideraçóes sobre a psicossomática psicanalítica de Pierre Marty. Tempo Psicanalítico.

Rocha, F. J. B. (1988). A psicanálise e os pacientes somatizantes: introdução às idéias de Joyce McDougall. Revista Brasileira de Psicanálise, 22 (1), 27-41. 
Rodrigues, A. L. \& Rodrigues, D. M. (1991). Introdução à história da medicina psicossomática. Revista Brasileira de Pesquisa em Psicologia, 3 (2), 79-85.

Santos Filho, O. C. (1993). Histeria, hipocondria e fenômeno psicossomático. Em Mello Filho, J. (Org.). Psicossomática hoje (pp. 108-112). Porto Alegre: Artes Médicas. . (1994). Psicanálise do paciente "psicossomático". Revista Brasileira de Psicanálise, 28 (1), 111-128.

Silva, A. F. R. \& Caldeira, G. (1993). Alexitimia e pensamento operatório: a questão do afeto na Psicossomática. Em Mello Filho, J. (Org.). Psicossomática hoje (pp. 113-118). Porto Alegre: Artes Médicas.

Smadja, C. (1995). Le modèle psychosomatique de Pierre Marty. Revue Française de Psychosomatique, 7, 7-25.

Vieira, W. C. (1997). A psicossomática de Pierre Marty. Em Ferraz, F. C. \& Volich, R. M. (Orgs.). Psicossoma: psicossomática psicanalítica (pp. 15-22). São Paulo: Casa do Psicólogo.

Volich, R. M. (2000). Psicossomática: de Hipócrates à Psicanálise. São Paulo: Casa do Psicólogo.

\section{NoTAS}

1 Esse termo será utilizado ao longo do texto para fazer referência aos portadores de doenças orgânicas - sobretudo, mas não somente crônicas não-transmissíveis - que apresentam alteraçôes das funções fisiológicas motivadas por fatores de natureza diversa.

Recebido em 6 de janeiro de 2006 Aceito para publicação em 16 de março de 2006 